\title{
The Varkud satellite ribozyme
}

\author{
DAVID M.J. LILLEY \\ Cancer Research UK Nucleic Acid Structure Research Group, Department of Biochemistry, The University of Dundee, Dundee DD1 5EH, UK
}

\begin{abstract}
The VS ribozyme is the largest nucleolytic ribozyme, for which there is no crystal structure to date. The ribozyme consists of five helical sections, organized by two three-way junctions. The global structure has been determined by solution methods, particularly FRET. The substrate stem-loop binds into a cleft formed between two helices, while making a loop-loop contact with another section of the ribozyme. The scissile phosphate makes a close contact with an internal loop (the A730 loop), the probable active site of the ribozyme. This loop contains a particularly critical nucleotide A756. Most changes to this nucleotide lead to three-orders of magnitude slower cleavage, and the Watson-Crick edge is especially important. NAIM experiments indicate that a protonated base is required at this position for the ligation reaction. A756 is thus a strong candidate for nucleobase participation in the catalytic chemistry.
\end{abstract}

Keywords: VS ribozyme; RNA catalysis; RNA structure

\section{INTRODUCTION}

The VS ribozyme is one of the class of nucleolytic ribozymes that includes the hammerhead, hairpin, and hepatitis delta virus ribozymes (Lilley 1999; Doudna and Cech 2002). These carry out reversible cleavage and ligation reactions at a specific site by transesterification reactions involving $2^{\prime}$ and $5^{\prime}$-oxygen and the $3{ }^{\prime}$-phosphorus atoms. The Varkud satellite (VS) RNA is an abundant transcript from DNA found in the mitochondria of a number of natural isolates of Neurospora. Collins and coworkers found that the VS RNA contains an element capable of self-cleavage (Saville and Collins 1990), which is thought to act in the processing of replication intermediates (Kennell et al. 1995). At $\sim 150$ nucleotides, the VS ribozyme is the largest of the nucleolytic ribozymes, and is now the only member of this group for which there is no crystal structure.

In terms of sequence, the VS ribozyme has nothing in common with the other nucleolytic ribozymes. Virtually all of the early work on this ribozyme was carried out in the

Reprint requests to: David M.J. Lilley, Cancer Research UK Nucleic Acid Structure Research Group, Department of Biochemistry, MSI/WTB Complex, The University of Dundee, Dundee DD1 5EH, UK; e-mail: d.m.j.lilley@dundee.ac.uk; fax: 44-1382-345893.

Abbreviations: VS, Varkud Satellite; HDV, Hepatitis delta virus; NMR, nuclear magnetic resonance; FRET, fluorescence resonance energy transfer; NAIM, nucleotide analog interference mapping; $\mathrm{S}_{\mathrm{N}} 2$, bimolecular nucleophilic substitution reaction; $\mathrm{pK}_{\mathrm{a}},-\log _{10}$ (acid dissociation constant).

Article and publication are at http://www.rnajournal.org/cgi/doi/ 10.1261/rna.5217104.
Collins laboratory. The secondary structure was deduced by a combination of probing and mutagenesis (Beattie et al. 1995). A 5' stem-loop structure (helix I) contains an internal loop in which the ribozyme cleavage occurs. This is linked to an H-shaped structure comprising helices II through VI (Fig. 1). Stem-loop I can be physically disconnected from the rest of the RNA, to create a ribozyme (helices II-VI) that acts in trans on the substrate (Guo and Collins 1995). The VS ribozyme is unique among the nucleolytic ribozymes in that the interaction between the ribozyme and its substrate involves essentially tertiary contacts. In this aspect, it resembles more the ribozymes RNaseP (Frank and Pace 1998), which cleaves pre-tRNAs, and group I self-splicing introns, which bind and cleave a short splice-site duplex RNA (Cech and Herschlag 1996). Part of this interaction is the formation of loop-loop pairing between the GAC triplet in the terminal loop of stem V, and a GUC triplet in the substrate (Rastogi et al. 1996). The latter is largely contained within the terminal loop, but exposure of the $3^{\prime}$ cytosine would require the opening of the terminal base pair, and it is proposed that this results in a change in the conformation of the substrate that is important for the cleavage reaction (Andersen and Collins 2000). In its trans-acting form, the ribozyme is very well behaved, especially if base pairing in helix Ia is absent (Fig. 2). The progress of the cleavage reaction is well fitted by a single exponential, and the kinetics conform to an enzyme-type scheme involving formation of a noncovalent complex followed by the chemical step, with values of $K_{d}=1 \mu \mathrm{M}$ and $\mathrm{k}_{2}=2 \min ^{-1}$ (Lafontaine et al. 2001b). 


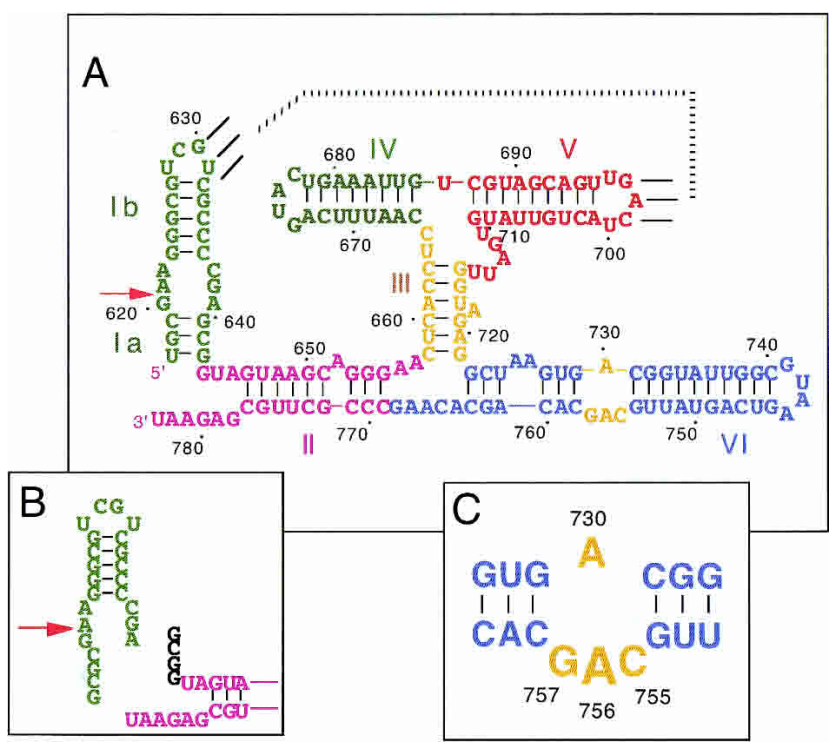

FIGURE 1. The sequence and secondary structure of the VS ribozyme. $(A)$ The sequence and deduced secondary structure of the VS ribozyme as determined by Collins and coworkers (Beattie et al. 1995), drawn in its cis-acting form. The position of cleavage is indicated by the arrow. The broken line indicates a 3-bp tertiary interaction between the loops of helices I and V (Rastogi et al. 1996). The color coding of the different helices has been used throughout this review. (B) The substrate may be separated from the ribozyme, which then acts in trans. (C) Close-up of the A730 loop, an important component of the active site of the ribozyme.

\section{THE STRUCTURE OF THE SUBSTRATE}

The substrate comprises a stem-loop, with an internal loop that includes the scissile phosphate. This is small enough to be amenable to structural analysis by NMR, and there have been several investigations. The first study was made on a form in which the upper stem-loop (helix Ib) was truncated to $3 \mathrm{bp}$ and terminated with a tetraloop (Michiels et al.
2000), whereas a complete substrate strand was studied in the second analysis (Flinders and Dieckmann 2001). Both studies found that the internal loop comprised two sheared G.A base pairs reminiscent of domain 2 of the hammerhead ribozyme (Pley et al. 1994; Scott et al. 1995) plus a protonated $\mathrm{A}^{+} \cdot \mathrm{C}$ base pair.

It has been proposed, on the basis of covariation analysis, that the loop-loop interaction between the substrate and stem $\mathrm{V}$ results in a rearrangement of the base pairing in stem Ib of the substrate (Andersen and Collins 2000). This involves the opening of the terminal base pair, the flipping out of C634, and rearrangement of base pairing in stem Ib, such that CCC (635-637) pairs with GGG (623-625). Recently, the NMR structure of a stabilized rearranged structure of the internal loop has been presented (Hoffmann et al. 2003). The sheared G620.A639 pair is preserved, but G638 now interacts in a noncoplanar manner with both A621 and A622, whereas A621 is cross-strand stacked onto A639 on the minor groove side. From chemical-shift changes on addition of magnesium ions, the presence of two ion-binding sites was deduced, one of which appears to be close to the cleavage site.

Although it is clear that some kind of structural changes in the substrate stem loop would be required to form the 3 bp with loop $\mathrm{V}$, the exact nature of this alteration is not yet fully clear. On interacting with stem-loop V, C634 exhibits enhanced reactivity to dimethyl sulphate (Andersen and Collins 2001), but this might result from less than total extrusion of the base from the helix. A number of sequence changes that would be expected to stabilize the altered pattern of base pairing in helix Ib lead to a substantial reduction in cleavage rate (D. Lafontaine, A. McLeod, and D.M.J. Lilley, unpubl.). But, in any case, it is highly probable that the structure of the substrate will be further altered when it interacts with the ribozyme. There is a clear precedent set by the hairpin ribozyme, in which the structures of the indi-

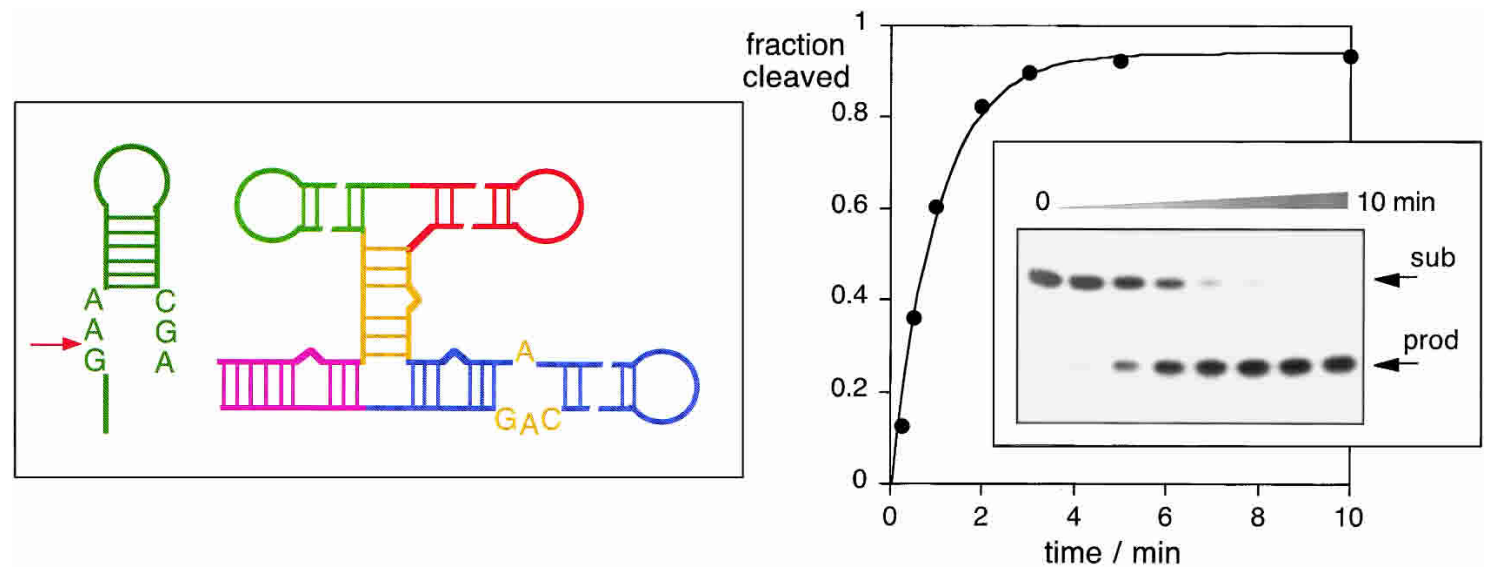

FIGURE 2. Substrate cleavage by the VS ribozyme in trans. Radioactively $5^{\prime}-{ }^{32} \mathrm{P}$-labeled substrate has been incubated with the five-helix VS ribozyme (left) under single-turnover conditions at $37^{\circ} \mathrm{C}$ in the presence of $10 \mathrm{mM}$ magnesium ions in a 10 -min time course. The substrate and 5 -nucleotide product were separated by gel electrophoresis, and an autoradiograph of the gel is shown. Reaction progress $(\mathbf{)})$ is plotted as a function of time, and fitted to a single-exponential function (solid line) giving an observed rate of $k_{o b s}=1 \mathrm{~min}^{-1}$. 
vidual A (Cai and Tinoco 1996) and B (Butcher et al. 1999) loops are significantly changed when they interact together in the complete ribozyme (Rupert and Ferré-D'Amaré 2001).

\section{THE STRUCTURE OF THE RIBOZYME}

In the absence of a crystal structure for the VS ribozyme (and not for want of trying), we are forced to adopt other approaches to try to determine the structure of the RNA, and there has been significant progress in the last $3 \mathrm{yr}$. Examination of the secondary structure of the ribozyme (Fig. 1) reveals that the $\mathrm{H}$-shaped structure is essentially organized by two three-way helical junctions; the 2-3-6 junction (between helices II, III, and VI) and the 3-4-5 junction (between helices III, IV, and V). The hammerhead and hairpin ribozymes also contain prominent helical junctions, and such junctions appear to be common central features of small, autonomously folding RNA species. Therefore, it seemed probable that the structures of the two junctions essentially determine the overall fold of the VS ribozyme.

The sequence of the VS ribozyme has been subjected to a large number of nucleotide changes to dissect the functionally important regions. The overall secondary structure is required for the function of the ribozyme, but in many cases, a base pair can be substituted by another without affecting activity, so long as the secondary structure is preserved. The majority of helix IV and the distal end of helix VI can be substantially deleted without significant loss of function (Lafontaine et al. 2002a). The lengths (but not sequence) of helices III and V are very important, and the sequence of the terminal loop of stem $\mathrm{V}$ cannot be changed without a major loss of activity. The base bulges in helices II and VI must be present for full activity, although they can be replaced by other nucleotides, so that their role is probably structural. The activity is strongly dependent on the local sequence of the two three-way junctions (Lafontaine et al. 2001a; Sood and Collins 2001; Lafontaine et al. 2002a), underlining their important role in the architecture of the ribozyme.

The global structures of the 2-3-6 and 3-4-5 junctions were determined by a combination of comparative gel electrophoresis and FRET (Lafontaine et al. 2001a, 2002a). Both undergo coaxial stacking of two arms, induced by the noncooperative binding of magnesium ions. Helices III and VI are coaxially stacked in the 2-3-6 junction, with an acute angle subtended between helices VI and II (Lafontaine et al. 2001a). By a happy coincidence, there is a three-way junction of very similar sequence present in $23 \mathrm{~S}$ rRNA. When transplanted into the VS ribozyme, good cleavage activity was preserved, so the structure is probably the same in each case. Globally, the two structures are identical, with equivalent helices coaxially stacked and similar inter-axial angles. We have therefore modeled the structure of the 2-3-6 junc- tion (Lafontaine et al. 2001a) based on that in the ribosome (Ban et al. 2000). The nucleotides A656 and G768 interact in a wedge-like manner that sets up the trajectory of helix II; changes in sequence at these positions are very detrimental to cleavage or ligation activity of the ribozyme (Lafontaine et al. 2001a) and are highly conserved in $23 \mathrm{~S}$ rRNA (Gutell et al. 2000). Helices IV and III are coaxially stacked in the 3-4-5 junction, and the smallest angle is subtended between helices III and V. Unfortunately, it was asking too much of chance to expect to find anything similar to this junction in the ribosome, so the local stereochemistry is unknown. However, it has been plausibly suggested that the formally single-stranded sequence between helices V and III adopts a UNR-type turn, and it has been found that activity is preserved if this is replaced by a stem-loop, that is, turning the 3-4-5 junction into a four-way helical junction (Sood and Collins 2001).

The two junctions are linked through the common helix III, generating a long tube comprising the coaxially stacked helices IV, III, and VI, from which helices V and II radiate. The dihedral angle between helices $\mathrm{V}$ and II was determined electrophoretically to be of the order of $75^{\circ}$ (Lafontaine et al. 2002a), thus generating a working model for the complete ribozyme (Fig. 3). No attempt has been made to represent the base bulges within this model. The single A-bulge in helix III can be replaced by an A-U base pair with no loss of activity. However, the bulges in helices II and VI would be expected to generate a local bending of the axes (Bhattacharyya et al. 1990; Gohlke et al. 1994; Zacharias and Hagerman 1995). This is probably rather important in the interaction between the ribozyme and substrate.
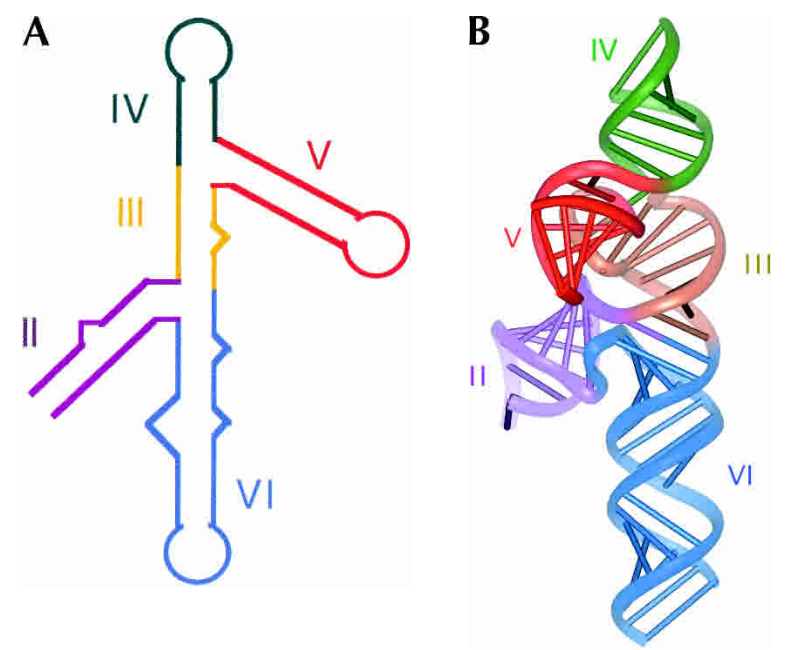

FIGURE 3. The structure of the ribozyme is organized by the two three-way junctions. (A) Schematic of the secondary structure of the ribozyme, drawn to correspond with the deduced three-dimensional structure. (B) A model for the complete 5-helix ribozyme. This was derived by assembling the two three-way junctions through their common helix III, using the dihedral angle between helices II and V measured by gel electrophoresis. 
Strobel and coworkers (Jones et al. 2001) examined the sequence of the Varkud plasmid flanking the ribozyme, and noted a significant complementarity that would generate an additional imperfect helix (termed VII), forming a third three-way junction with helices Ia and II. They observed that forms of the ribozyme containing at least part of this helix carried out a ligation reaction, but that this was improved significantly by some sequence variants in helix VII. They suggest that the helical junction can exist in two forms that differ in their base pairing.

\section{THE INTERACTION BETWEEN RIBOZYME AND SUBSTRATE}

Two points of attachment of the substrate to the ribozyme are fairly clear. First, in the natural cis-acting form, the end of helix Ia is connected to the $5^{\prime}$ end of helix II by three nucleotides, and therefore, these helical ends must be relatively close in space. Second, to make the loop-loop interaction, the terminal loop of helix Ib must physically contact that of helix V. If we place the substrate onto the lowresolution model of the ribozyme (Fig. 3) subject to these constraints, we have little choice but to dock it into the cleft formed between helices II and VI, as indicated in Figure 4 (Lafontaine et al. 2002a). This naturally brings the cleavage site into close proximity with the A730 loop of stem VI, which we discuss in the next section. There could be an element of induced fit on binding that would improve the ribozyme-substrate interaction further. Helix Ia of the sub-
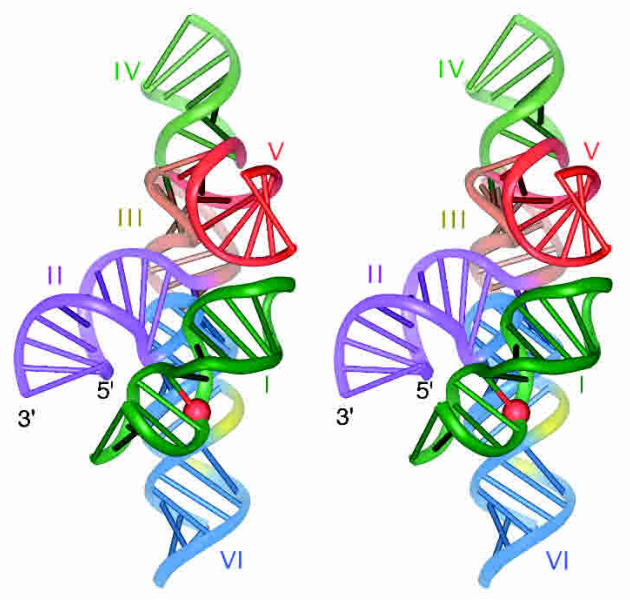

FIGURE 4. A parallel-eye stereographic representation of the interaction between the VS ribozyme and its substrate stem-loop. An NMR-derived structure of the substrate stem-loop (Flinders and Dieckmann 2001) has been docked into the ribozyme model, such that the open end could be connected to the end of helix II, and the loop is close to that of helix V. The scissile phosphate of the substrate is highlighted spacefilling in red; note that this is adjacent to the A730 loop, which is colored yellow. strate essentially protrudes unhindered from the lower end of the complex; we have found that this helix can be extended considerably without loss of catalytic activity, consistent with this prediction (McLeod and Lilley 2004). Helix I can be attached to the ribozyme in a number of different ways with preservation of activity. It can be attached to the $3^{\prime}$ end of helix II (instead of the normal $5^{\prime}$ attachment; Rastogi and Collins 1998), and it can even be attached to the end of helix VI via a linker (D.A. Lafontaine and D.M.J. Lilley, unpubl.). These observations are readily accommodated within the model.

Most of the sequence requirements for the ribozyme can be rationalized in terms of the requirements for substrate binding. Many of the sequence changes that affect activity are found in the two junctions that organize the global architecture of the ribozyme. We have found an excellent correlation between sequence changes in the 2-3-6 junction that affect its ion-induced folding, and those that affect the activity of the complete ribozyme (Lafontaine et al. 2001a). Cleavage and ligation activity are both exquisitely sensitive to the lengths of helices III and V. The latter can readily be understood in terms of the required spatial and rotational setting of the loop of helix $\mathrm{V}$ to interact correctly with that of the substrate. The length of helix III is clearly important, because it determines the dihedral angle between helices II and $\mathrm{V}$, both of which interact with the substrate. The dependence of cleavage rate on the length of helix III can be well fitted on the assumption that the increase in activation energy results from the requirement to distort that dihedral angle back to the optimal, which should be proportional to the square of the displacement angle (Lafontaine et al. 2002a).

Hydroxyl radical probing of a covalently continuous substrate-ribozyme construct has revealed a very prominent region of protection of both strands of helix II adjacent to the 2-3-6 junction upon folding (Hiley and Collins 2001). This is consistent with a close association between the substrate and helix II in this region, as might be anticipated if the substrate is accommodated in the cleft between helices II and VI. It has been suggested that the interaction might be mediated by 2 '-hydroxyl groups on the substrate and helix II (Sood et al. 2002). Using nucleotide analog-interference mapping (NAIM; Ryder and Strobel 1999), positions sensitive to removal of $2^{\prime}$-hydroxyl groups were identified at the junction-proximal end of helix II (Sood et al. 2002), in similar locations to those protected against radical attack. Similar observations by Jones and Strobel (2003) led them to suggest the formation of an A-minor motif. Sood et al. (2002) also observed that 2'-hydroxyl groups in the block of cytosine nucleotides of helix Ib (634-637) also lead to lowered activity, leading to the proposal of an interaction between substrate and helix II. However, single substitution of these positions resulted in no loss of activity (Tzokov et al. 2002), weakening the case for some kind of ribose zipper-type interaction. 


\section{THE ACTIVE SITE OF THE RIBOZYME}

Most of the sequence variants of the ribozyme that affect catalytic activity can be explained in terms of structural consequences. These are found mainly in the helical junctions, the bulges, or in the lengths of critical helices, notably III and V, as discussed previously. However, there is one major exception to this. Most single-base changes introduced into the internal loop of helix VI that contains A730 (consequently, generally referred to as the A730-loop) lead to significant loss of cleavage activity (observed cleavage rate lowered by 50 -fold or more) in trans (Lafontaine et al. 2001b) and in cis (Sood and Collins 2002). Yet, we can detect no significant changes to the folding of the ribozyme or its components resulting from these substitutions (Lafontaine et al. 2001b). The introduction of a variety of nucleotide analogs into the A730 loop also resulted in strong interference with ligation in NAIM experiments (Jones and Strobel 2003). The loop was also found to be subject to ethylation interference, and contained sites of interference by phosphorothioate incorporation and suppression by the more thiophilic manganese ions (Sood et al. 1998).

Taken together, these data suggest that the A730 loop is of great importance in the function of the ribozyme, and is therefore likely to be a significant part of the active site of the ribozyme. Thus, we expect that the ribozyme functions by docking the substrate into the cleft between helices II and VI, to facilitate an intimate interaction between the cleavage site and the A730 loop. The coalescence of the two generates the local environment in which catalysis can proceed, perhaps in a manner reminiscent of the loop-loop interaction in the hairpin ribozyme (Murchie et al. 1998; Rupert and Ferré-D'Amaré 2001). In the low-resolution model of the ribozyme, it is easy to juxtapose the scissile phosphate (shown as a red sphere in Fig. 4) with the A730 loop.

Within the A730 loop, one particular nucleotide stands out. Substitution of A756 by G, C, or U leads to at least 300-fold loss of cleavage (Lafontaine et al. 2001b) and ligation activity (McLeod and Lilley 2004). These changes have only a small effect on the $\mathrm{K}_{\mathrm{d}}$ for substrate binding (around fivefold or less), and most of the effect arises from a reduced rate of central conversion of the substrate into product $\left(\mathrm{k}_{2}\right.$; Lafontaine et al. 2001b). In a recent study (Hiley et al. 2002), a ribozyme with a covalently attached substrate containing 4-thiouridine at the cleavage site (nucleotide 621, adjacent to the cleavage position) was irradiated with UV light. A strong cross-link was obtained, which mapped to A756. This places A756 in the putative active site physically close to the cleavage site in the substrate.

A756 has been analyzed by systematic functional group modification (Lafontaine et al. 2002b). Removal of the 2'hydroxyl group results in a 10-fold reduction in observed cleavage rate, whereas ablation of the base lowers the activity $\geq 1000$-fold. Removal of the exocyclic amine from the 6 position (purine), translocation to the 2 position (2-aminopurine), or addition of a 2-amino group (2,6 diaminopurine) all lead to 1000 -fold slower cleavage, and even methylation of the amino group (6-methyladenine) resulted in an 80-fold reduced cleavage rate. In contrast, replacement of N7 by CH (7-deaza adenosine) had a negligible effect on activity. It appears that the nucleobase of A756 is important for catalytic activity, and more specifically, the WatsonCrick edge of the base. An even wider range of nucleotide analogs was used in a NAIM experiment (Jones and Strobel 2003), in which it was found that the 756 position was the most consistently sensitive nucleotide in the entire ribozyme in terms of interference with the ligation reaction. But, perhaps the most interesting observation was that when either purine or 8-aza-adenosine were introduced at this site, interference was largely suppressed by lowering the $\mathrm{pH}$ to 5.4 .

All of the available data point to an important role for A756 in the catalytic function of the VS ribozyme, and it is tempting to speculate that the nucleobase plays a direct role in the chemistry of the transesterification reactions. We cannot exclude the possibility that the role of A756 is essentially structural, although, if this were the case, it is surprising that sequence or functional group changes that affect activity in a major way have such small effects on substrate binding or folding. Nevertheless, at the present time it cannot be said that there is a smoking gun.

\section{POSSIBLE CATALYTIC MECHANISMS}

The evidence is fairly compelling that the A730 loop is the active site of the VS ribozyme, and that A756 plays a key role of some kind. But how does the interaction with the substrate accelerate the transesterification reaction by a factor of at least $10^{5}$ ?

The generally accepted reaction mechanism for all the nucleolytic ribozymes is shown in Figure 5. The cleavage reaction proceeds by a nucleophilic attack of the $2^{\prime}$-oxygen on the $3^{\prime}$-phosphorus in an $\mathrm{S}_{\mathrm{N}} 2$ reaction, with departure of the $5^{\prime}$-oxygen, leaving a cyclic $2^{\prime} 3^{\prime}$ phosphate. The ligation reaction is the reverse, in which the $5^{\prime}$-oxygen attacks the $3^{\prime}$-phosphorus of the cyclic phosphate. The details of how ribozymes catalyze these reactions have been rather controversial, but there is now some consensus emerging on the general nature of the catalysis. We can identify three broad ways in which the reaction depicted in Figure 5 could be catalyzed by a ribozyme. Firstly, general acid-base catalysis might be used to increase the strength of the oxygen nucleophiles by removal of bonded protons, and to stabilize the oxyanion leaving groups by protonation. It should be noted that the principle of microscopic reversibility dictates that if a group is behaving as a general base in (say) the cleavage reaction, then it must act as a general acid in the ligation reaction. Solvated metal ions might act in general 


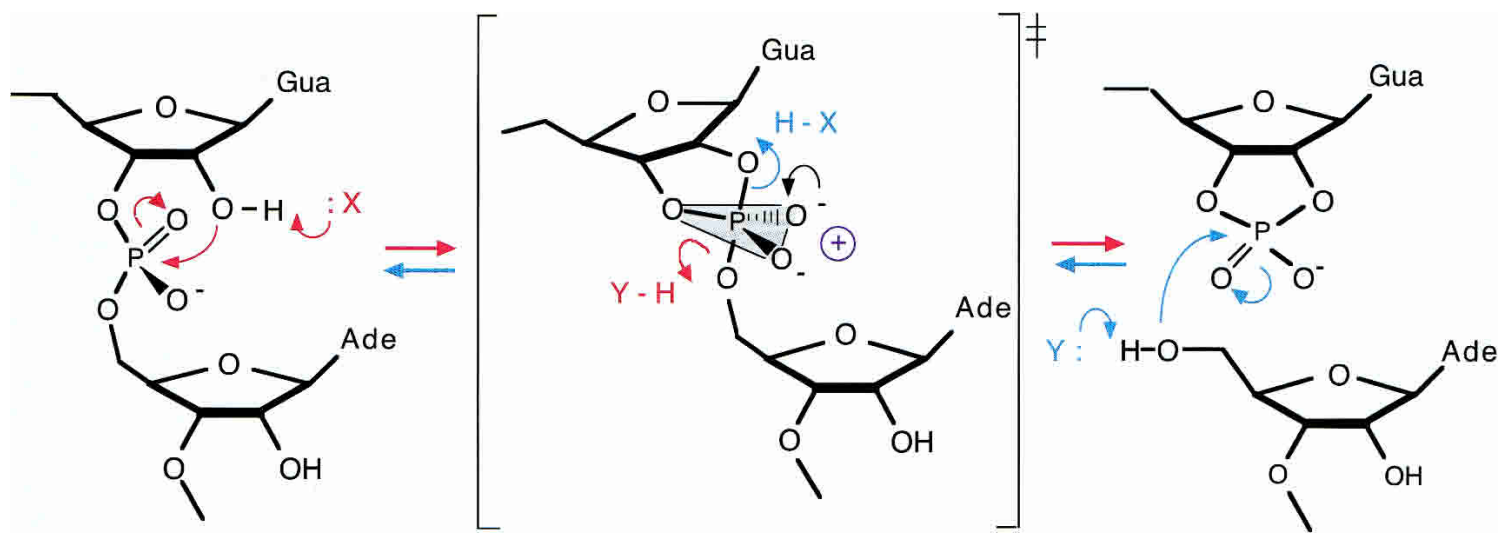

FIGURE 5. The reaction mechanism for cleavage and ligation by the VS ribozyme. In the cleavage reaction (right, red) the $3^{\prime}$-phosphorus is attacked by the $2^{\prime}$-oxgen, with departure of the $5^{\prime}$-oxygen to leave a cyclic $2^{\prime} 3^{\prime}$-phosphate. In the ligation reaction (left, blue) the attacking nucleophile is the $5^{\prime}$-oxygen, with departure of the $3^{\prime}$-oxygen to form the internucleotide phosphodiester linkage. The reaction could be accelerated by general acid-base catalysis, whereby the attacking nucleophile is deprotonated by a base, and the leaving oxyanion is protonated by an acid. Note that a given group must fulfill opposite functions in the two reactions. The transition state for the reaction is a doubly charged oxyphosphorane, which could be stabilized in various ways, including the juxtaposition of positive charge. In the transition state, the $2^{\prime}$-oxygen, $3^{\prime}$-phosphorus, and $5^{\prime}$-oxygen are colinear, and the local RNA structure could be exploited to align the reactants in an optimal manner for reaction.

acid-base catalysis. Alternatively, metal ions might act as Lewis acids, directly bound as innersphere complexes, to polarize phosphate oxygen atoms. However, it has been shown that the VS (and other nucleolytic) ribozymes exhibit good cleavage activity in high concentrations of monovalent ions (Murray et al. 1998), so site-specific binding is unlikely to be essential for all ribozyme activity. On the other hand, cleavage activity was not supported in hexammine cobalt (III) ions either in cis (Maguire and Collins 2001) or trans (D.A. Lafontaine and D.M.J. Lilley, unpubl.), suggesting that water of hydration is important.

Nucleobases could also participate in general acid-base chemistry. The best precedent for this is the role of cytosine 75 in the hepatitis delta virus (HDV) ribozyme (Ferréd'Amaré et al. 1998; Perrotta et al. 1999; Nakano et al. 2000), and evidence is growing in the hairpin ribozyme (Pinard et al. 2001; Rupert et al. 2002). Clearly, A756 must be a candidate for this role in the VS ribozyme. The rate of the cleavage reaction is not significantly dependent on $\mathrm{pH}$ (Rastogi and Collins 1998), unlike that for the hammerhead reaction (Dahm et al. 1993), but $\mathrm{pH}$ dependence corresponding to a $\mathrm{pK}_{\mathrm{a}}$ of 5.6 has been observed for the ligation reaction (McLeod and Lilley 2004). The restoration of good ligation activity in VS ribozyme variants with nucleotide bases of reduced $\mathrm{pK}_{\mathrm{a}}$ at lowered $\mathrm{pH}$ and stimulation of activity in variants with nucleotide bases of increased $\mathrm{pK}_{\mathrm{a}}$ point to a requirement for a protonated base at position 756 (Jones and Strobel 2003). In contrast to the HDV ribozyme (Perrotta et al. 1999), no rescue of activity of VS ribozyme with substituted bases or an abasic site could be obtained by addition of exogenous imidazole in the medium (Lafontaine et al. 2002b). However, addition of adenine also failed to restore activity to these variants, so it is likely that the site is simply inaccessible to bases from the medium.
A second catalytic strategy is likely to be stabilization of the pentacovalent phosphate of the reaction transition state. This might involve the formation of new hydrogen bonds, as has been observed in the hairpin ribozyme (Rupert et al. 2002). It could also be electrostatic in nature, juxtaposing positive charge to stabilize the doubly negatively charged oxyphosphorane transition state. Metal ions might carry out this role, and it is possible that high concentrations of monovalent ions might act in this way. Alternatively, a positively charged nucleobase could do the job-another potential role for A756.

Last, local RNA conformation could be important in catalysis, conferring the advantages of proximity and orientation. This might facilitate the in-line trajectory into the trigonal bipyramidal transition state and alignment and proximity of the substrates for the ligation reaction. It is hard to evaluate the significance of this factor in the VS ribozyme.

\section{CONCLUSION}

The global architecture of the VS ribozyme is organized by two three-way helical junctions, which undergo ion-induced folding. The lower junction generates a cleft between helices II and VI, into which the substrate stem-loop structure binds, while making a loop-loop contact with stemloop $\mathrm{V}$ that is positioned by the upper junction. Once the substrate is bound, it can make an intimate contact with the A730 loop within helix VI - this appears to be the active site of the ribozyme. Within this loop, a particularly critical role seems to be played by A756, which is a strong candidate for direct nucleobase participation in the phosphoryl transfer chemistry. 


\section{ACKNOWLEDGMENTS}

We thank Daniel Lafontaine, David Norman, Aileen McLeod, and Tim Wilson for their major contributions to the study of the VS ribozyme in Dundee, and Cancer Research UK and the BBSRC for financial support.

\section{REFERENCES}

Andersen, A.A. and Collins, R.A. 2000. Rearrangement of a stable RNA secondary structure during VS ribozyme catalysis. Mol. Cell 5: 469-478.

- 2001. Intramolecular secondary structure rearrangement by the kissing interaction of the Neurospora VS ribozyme. Proc. Natl. Acad. Sci. 98: 7730-7735.

Ban, N., Nissen, P., Hansen, J., Moore, P.B., and Steitz, T.A. 2000. The complete atomic structure of the large ribosomal subunit at $2.4 \AA$ resolution. Science 289: 905-920.

Beattie, T.L., Olive, J.E., and Collins, R.A. 1995. A secondary-structure model for the self-cleaving region of Neurospora VS RNA. Proc. Natl. Acad. Sci. 92: 4686-4690.

Bhattacharyya, A., Murchie, A.I.H., and Lilley, D.M.J. 1990. RNA bulges and the helical periodicity of double-stranded RNA. Nature 343: 484-487.

Butcher, S.E., Allain, F.H., and Feigon, J. 1999. Solution structure of the loop B domain from the hairpin ribozyme. Nat. Struct. Biol. 6: 212-216.

Cai, Z.P. and Tinoco, I. 1996. Solution structure of loop A from the hairpin ribozyme from tobacco ringspot virus satellite. Biochemistry 35: 6026-6036.

Cech, T.R. and Herschlag, D. 1996. Group I ribozymes: Substrate recognition, catalytic strategies and comparative mechanistic analysis. In RNA catalysis (eds. F. Eckstein and D.M.J. Lilley), Vol. 10, pp. 1-17. Springer-Verlag, Heidelberg, Germany.

Dahm, S.C., Derrick, W.B., and Uhlenbeck, O.C. 1993. Evidence for the role of solvated metal hydroxide in the hammerhead cleavage mechanism. Biochemistry 32: 13040-13045.

Doudna, J.A. and Cech, T.R. 2002. The chemical repertoire of natural ribozymes. Nature 418: 222-228.

Ferré-d'Amaré, A.R., Zhou, K., and Doudna, J.A. 1998. Crystal structure of a hepatitis delta virus ribozyme. Nature 395: 567-574.

Flinders, J. and Dieckmann, T. 2001. A pH controlled conformational switch in the cleavage site of the VS ribozyme substrate RNA. J. Mol. Biol. 308: 665-679.

Frank, D.N. and Pace, N.R. 1998. Ribonuclease P: Unity and diversity in a tRNA processing ribozyme. Annu. Rev. Biochem. 67: 153-180.

Gohlke, C., Murchie, A.I.H., Lilley, D.M.J., and Clegg, R.M. 1994. The kinking of DNA and RNA helices by bulged nucleotides observed by fluorescence resonance energy transfer. Proc. Natl. Acad. Sci. 91: 11660-11664.

Guo, H.C.T. and Collins, R.A. 1995. Efficient trans-cleavage of a stemloop RNA substrate by a ribozyme derived from Neurospora VS RNA. EMBO J. 14: 368-376.

Gutell, R.R., Subashchandran, S., Schnare, M., Du, Y., Lin, N., Madabusi, L., Muller, K., Pande, N., Yu, N., Shang, Z., et al. 2000. Comparative sequence analysis and the prediction of RNA structure, and the web. http://www.rna.icmb.utexas.edu/.

Hiley, S.L. and Collins, R.A. 2001. Rapid formation of a solventinaccessible core in the Neurospora Varkud satellite ribozyme. EMBO J. 20: 5461-5469.

Hiley, S.L., Sood, V.D., Fan, J., and Collins, R.A. 2002. 4-thio-U crosslinking identifies the active site of the VS ribozyme. EMBO J. 21: 4691-4698.

Hoffmann, B., Mitchell, G.T., Gendron, P., Major, F., Andersen, A.A., Collins, R.A., and Legault, P. 2003. NMR structure of the active conformation of the Varkud satellite ribozyme cleavage site. Proc. Natl. Acad. Sci. 100: 7003-7008.

Jones, F.D. and Strobel, S.A. 2003. Ionization of a critical adenosine residue in the Neurospora Varkud Satellite ribozyme active site. Biochemistry 42: 4265-4276.

Jones, F.D., Ryder, S.P., and Strobel, S.A. 2001. An efficient ligation reaction promoted by a Varkud Satellite ribozyme with extended 5'- and 3'-termini. Nucleic Acids Res. 29: 5115-5120.

Kennell, J.C., Saville, B.J., Mohr, S., Kuiper, M.T., Sabourin, J.R., Collins, R.A., and Lambowitz, A.M. 1995. The VS catalytic RNA replicates by reverse transcription as a satellite of a retroplasmid. Genes. \& Dev. 9: 294-303.

Lafontaine, D.A., Norman, D.G., and Lilley, D.M.J. 2001a. Structure, folding and activity of the VS ribozyme: Importance of the 2-3-6 helical junction. EMBO J. 20: 1415-1424.

Lafontaine, D.A., Wilson, T.J., Norman, D.G., and Lilley, D.M.J. 2001b. The A730 loop is an important component of the active site of the VS ribozyme. J. Mol. Biol. 312: 663-674.

Lafontaine, D.A., Norman, D.G., and Lilley, D.M.J. 2002a. The global structure of the VS ribozyme. EMBO J. 21: 2461-2471.

Lafontaine, D.A., Wilson, T.J., Zhao, Z.-Y., and Lilley, D.M.J. $2002 \mathrm{~b}$. Functional group requirements in the probable active site of the VS ribozyme. J. Mol. Biol. 323: 23-34.

Lilley, D.M.J. 1999. Structure, folding and catalysis in the small nucleolytic ribozymes. Curr. Opin. Struct. Biol. 9: 330-338.

Maguire, J.L. and Collins, R.A. 2001. Effects of cobalt hexammine on folding and self-cleavage of the Neurospora VS ribozyme. J. Mol. Biol. 309: 45-56.

McLeod, A.C. and Lilley, D.M.J. 2004. Efficient, pH-dependent RNA ligation by the VS ribozyme in trans. Biochemistry (in press).

Michiels, P.J.A., Schouten, C.H.J., Hilbers, C.W., and Heus, H.A. 2000. Structure of the ribozyme substrate hairpin of Neurospora VS RNA: A close look at the cleavage site. RNA 6: 1821-1832.

Murchie, A.I.H., Thomson, J.B., Walter, F., and Lilley, D.M.J. 1998. Folding of the hairpin ribozyme in its natural conformation achieves close physical proximity of the loops. Mol. Cell 1: 873881.

Murray, J.B., Seyhan, A.A., Walter, N.G., Burke, J.M., and Scott, W.G. 1998. The hammerhead, hairpin and VS ribozymes are catalytically proficient in monovalent cations alone. Chem. Biol. 5: 587-595.

Nakano, S., Chadalavada, D.M., and Bevilacqua, P.C. 2000. General acid-base catalysis in the mechanism of a hepatitis delta virus ribozyme. Science 287: 1493-1497.

Perrotta, A.T., Shih, I., and Been, M.D. 1999. Imidazole rescue of a cytosine mutation in a self-cleaving ribozyme. Science 286: 123-126.

Pinard, R., Hampel, K.J., Heckman, J.E., Lambert, D., Chan, P.A., Major, F., and Burke, J.M. 2001. Functional involvement of G8 in the hairpin ribozyme cleavage mechanism. EMBO J. 20: 6434-6442.

Pley, H.W., Flaherty, K.M., and McKay, D.B. 1994. Three-dimensional structure of a hammerhead ribozyme. Nature 372: 68-74

Rastogi, T. and Collins, R.A. 1998. Smaller, faster ribozymes reveal the catalytic core of Neurospora VS RNA. J. Mol. Biol. 277: 215-224.

Rastogi, T., Beattie, T.L., Olive, J.E., and Collins, R.A. 1996. A longrange pseudoknot is required for activity of the Neurospora VS ribozyme. $E M B O$ J. 15: 2820-2825.

Rupert, P.B. and Ferré-D'Amaré, A.R. 2001. Crystal structure of a hairpin ribozyme-inhibitor complex with implications for catalysis. Nature 410: 780-786.

Rupert, P.B., Massey, A.P., Sigurdsson, S.T., and Ferré-D’Amaré, A.R. 2002. Transition state stabilization by a catalytic RNA. Science 298: 1421-1424.

Ryder, S.P. and Strobel, S.A. 1999. Nucleotide analog interference mapping. Methods 18: 38-50.

Saville, B.J. and Collins, R.A. 1990. A site-specific self-cleavage reaction performed by a novel RNA in Neurospora mitochondria. Cell 61: 685-696.

Scott, W.G., Finch, J.T., and Klug, A. 1995. The crystal structure of an all-RNA hammerhead ribozyme: A proposed mechanism for RNA catalytic cleavage. Cell 81: 991-1002.

Sood, V.D. and Collins, R.A. 2001. Functional equivalence of the uridine turn and the hairpin as building blocks of tertiary structure in the Neurospora VS ribozyme. J. Mol. Biol. 313: 1013-1019. 
2002. Identification of the catalytic subdomain of the VS ribozyme and evidence for remarkable sequence tolerance in the active site loop. J. Mol. Biol. 320: 443-454.

Sood, V.D., Beattie, T.L., and Collins, R.A. 1998. Identification of phosphate groups involved in metal binding and tertiary interactions in the core of the Neurospora VS ribozyme. J. Mol. Biol. 282: 741-750.

Sood, V.D., Yekta, S., and Collins, R.A. 2002. The contribution of
2 '-hydroxyls to the cleavage activity of the Neurospora VS ribozyme. Nucleic Acids Res. 30: 1132-1138.

Tzokov, A.B., Murray, I.A., and Grasby, J.A. 2002. The role of magnesium ions and $2^{\prime}$-hydroxyl groups in the VS ribozyme-substrate interaction. J. Mol. Biol. 324: 215-226.

Zacharias, M. and Hagerman, P.J. 1995. Bulge-induced bends in RNA: Quantification by transient electric birefringence. J. Mol. Biol. 247: 486-500. 

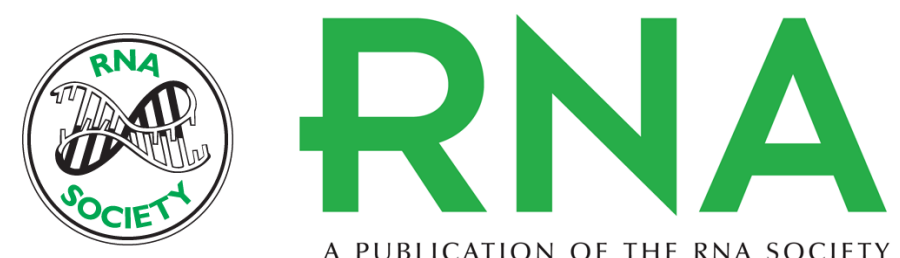

A PUBLICATION OF THE RNA SOCIETY

\title{
The Varkud satellite ribozyme
}

\author{
DAVID M.J. LILLEY
}

RNA 2004 10: 151-158

References This article cites 46 articles, 12 of which can be accessed free at: http://rnajournal.cshlp.org/content/10/2/151.full.html\#ref-list-1

\section{License}

Email Alerting Receive free email alerts when new articles cite this article - sign up in the box at the Service top right corner of the article or click here. 